\title{
SYMPOSIUM
}

\section{Confabulation in schizophrenia: A neuropsychological study}

\author{
E. LORENTE-ROVIRA, ${ }^{1}$ J.L. SANTOS-GÓMEZ, ${ }^{2}$ M. MORO, ${ }^{3}$ J.M. VILLAGRÁN, ${ }^{4}$ AND P.J. MCKENNA ${ }^{5}$ \\ ${ }^{1}$ Clinic University Hospital, Valencia, AVS and CIBERSAM, Spain \\ ${ }^{2}$ Psychiatry Unit, Virgen de la Luz Hospital, Cuenca, Spain \\ ${ }^{3}$ Basic Psychology, Clinic Psychology and Psychobiology Department, Jaume I University, Castellón, Spain \\ ${ }^{4}$ Psychiatry Hospitalization Unit, Jerez de la Frontera Hospital, Cádiz (SAS), Spain \\ ${ }^{5}$ Benito Menni CASM, Sant Boi de Llobregat, Barcelona and CIBERSAM, Spain
}

(Received December 22, 2009; Final Revision June 4, 2010; AcCepted June 4, 2010)

\begin{abstract}
Confabulation has been documented in schizophrenia, but its neuropsychological correlates appear to be different from those of confabulation in neurological disease states. Forty-five schizophrenic patients and 37 controls were administered a task requiring them to recall fables. They also underwent testing with a range of memory and executive tasks. The patients with schizophrenia produced significantly more confabulations than the controls. After correcting for multiple comparisons, confabulation was not significantly associated with memory impairment, and was associated with impairment on only one of eight executive measures, the Brixton Test. Confabulation scores were also associated with impairment on two semantic memory tests. Confabulation was correlated with intrusion errors in recall, but not false positive errors in a recognition task. The findings suggest that confabulation in schizophrenia is unrelated to the episodic memory impairment seen in the disorder. However, the association with a circumscribed deficit in executive function could be consistent with a defective strategic retrieval account of confabulation similar to that of Moscovitch and co-workers, interacting with defective semantic memory. (JINS, 2010, 16, 1018-1026.)
\end{abstract}

Keywords: Schizophrenia, Confabulation, Intrusion errors, Episodic memory, Executive dysfunction, Semantic memory dysfunction

\section{INTRODUCTION}

Confabulation, the production of false memories without deliberate intent to lie, is typically seen in patients with neurological disease, where it has been extensively studied (e.g., Gilboa \& Moscovitch, 2002; Glowinski, Payman, \& Frenchman, 2008; Schnider, 2008). Most authors (see Kopelman, 1987) recognize two varieties of the phenomenon, spontaneous confabulation, where the patient produces a free flow of false memories; and provoked confabulation, where the falsifications only occur fleetingly, for example, when the subject is challenged in a memory test. Confabulation is typically seen in patients who have amnesia from diverse causes, but a substantial body of recent work also emphasizes its relationship with frontal lobe damage (Gilboa \& Moscovitch, 2002; Turner, Cipolotti, Yousry, \& Shallice, 2008). At the neuropsychological level, most studies

Correspondence and reprint requests to: E. Lorente-Rovira, Centro de Salud Mental de la Malvarrosa, Avda. Malvarrosa, 10, 46011, Valencia, Spain. E-mail: esterlorente@hotmail.com have found that confabulation is associated with a combination of memory and executive impairment (e.g., Baddeley \& Wilson, 1988; Cunningham, Pliskin, Cassisi, Tsang, \& Rao, 1997; DeLuca, 1993; Fischer, Alexander, D’Esposito, \& Otto, 1995; Hashimoto, Tanaka, \& Nakano, 2000; Mercer, Wapner, Gardner, \& Benson, 1977; Stuss, Alexander, Lieberman, \& Levine, 1978; for a review, see DeLuca, 2000). However, while the former appears to be present in all cases, confabulating patients have been described who lack clear executive deficits (Dab, Claes, Morais, \& Shallice, 1999; Delbecq-Derouesné, Beauvois, \& Shallice, 1990).

Confabulation, or something closely similar to it, also occurs in a psychiatric disorder, schizophrenia. As long ago as 1913, Kraepelin described psychotic patients who spontaneously produced a wealth of false memories; these could be absolutely fixed and repeated again and again in almost exactly the same words, but more typically further details would be added on questioning and the stories would undergo a progressive embroidering. This phenomenon continues to be recognized as a rare symptom of schizophrenia, where it is referred to it as delusional confabulation (Wing, 
Cooper, \& Sartorius, 1974), reflecting the fact that, like delusions in general, the memories tend to be bizarre, fantastic, or downright impossible. In one of the very few contemporary examples of this form of confabulation, McKenna (2007) described a schizophrenic patient who, when he was questioned about violent ideas he had expressed to a psychologist, launched into the following account:

Patient: OK I'll tell you what happened. In 1978 I shot a man in the back of the head in a shop in Cambridge. I put one cartridge into him. My brother David put about eight into him. I shot a man in the leg called Conrad Carlton.

Interviewer: When was this?

Patient: About 1978. I frogmarched him from St. Neots right into the Midlands with a shotgun pointed at him. It was an empty shotgun.

Interviewer: Was this on foot?

Patient: Yeah. Right into the Midlands, about 80-odd miles

Interviewer: Both walking?

Patient: Yeah, I did. I was on the television.

Interviewer: How did you end up on television?

Patient: Because I had a shotgun pointed at him, you know. I was sort of notorious, you know we had a bit of fame-well the wrong sort of fame-but, you know, we got into a sort of contest and he could have lost his life. If I had aimed a few inches higher I could have killed him.

He then went on to recount how a criminal gang had murdered his father some years previously, and had also shot him (the patient) in the head, wounding but not killing him. Despite this, he went to work the next day, where his boss noticed the hole in his head and sent him to hospital!

Recently, another type of confabulation has been described in schizophrenia, akin to the provoked form of confabulation in neurological disease. Nathaniel-James and Frith (1996) asked 12 schizophrenic patients and 12 controls to recall a series of fables. All of the patients included some information which was not present in the narrative, whereas only one of controls did so. Several further studies have replicated this finding using recall of fables (Dab, Morais, \& Frith, 2004; Lorente-Rovira, Pomarol-Clotet, McCarthy, Berrios, \& McKenna, 2007), recall of stories similar to those in the logical memory subtest of the Weschler Memory Test (Dab et al., 2004; Salazar-Fraile et al., 2004), scripts (Simpson \& Done, 2002), or a task where the patients had to tell a story from pictures (Kramer, Bryan, \& Frith, 1998).

Patients with schizophrenia show varying but overall substantial degrees of cognitive impairment (Heinrichs \& Zakzanis, 1998), and this affects particularly long-term memory and executive function (see McKenna, Ornstein, \& Baddeley, 2002; Reichenberg \& Harvey, 2007). It is, therefore, of some interest to know whether the neuropsychological correlates of schizophrenic confabulation are similar to those seen in neurological disorders. In their original study, Nathaniel-James and Frith (1996) found that confabulation was associated with poor recall of the fables, but not with impairment on any of a range of other memory tests. Subsequently, they argued on the basis of an analysis of single cases that that episodic memory impairment was neither a necessary nor sufficient condition for confabulation to occur (Nathaniel-James, Foong, \& Frith, 1996), a conclusion which has been supported by several further studies (Dab et al., 2004; Kramer et al., 1998; Lorente-Rovira et al., 2007). There is less of a consensus about whether schizophrenic confabulation is associated with executive impairment. Nathaniel-James and Frith (1996) found a relationship between confabulation and impairment on the Hayling test, which requires inhibition of prepotent responses, but not with impairment on two other executive tests, the Wisconsin Card Sorting Test and verbal fluency. A multiple single-case study of five patients by Dab et al. (2004), four of whom produced confabulations, also suggested an association with poor performance on the Hayling test. However, this association was not found by Lorente-Rovira et al. (2007), and Salazar-Fraile et al. (2004) failed to find any relationship with performance on the Stroop test. Findings with respect to other executive tests have been conflicting (Dab et al., 2004; Lorente-Rovira et al., 2007; Nathaniel-James et al., 1996; Salazar-Fraile et al., 2004).

Nevertheless, it might be premature to conclude that confabulation in schizophrenia has a different neuropsychological signature from confabulation in neurological disease. For one thing, although memory impairment is invariably present in neurological confabulators, it appears to play only a "permissive" role, as noted above; a lack of relationship between confabulation and the severity of episodic memory impairment has also been documented in one study (Mercer et al., 1977). For another, some studies in neurological patients have found associations between confabulation and only certain forms of executive dysfunction, for example, working memory, set shifting and perseveration (Fischer et al., 1995); sustained attention, set shifting and mental tracking (Cunningham et al., 1997); or inhibition of prepotent responses and verbal fluency (Turner et al., 2008).

On the basis of such findings, Turner et al. (2008) have argued that that there is a confabulation-specific frontal deficit which is not well-captured by conventional executive tests. One class of current theoretical approaches to confabulation also proposes something similar, suggesting that confabulation results from a failure to monitor retrieved memories, or a failure in other strategic processes related to memory retrieval (Burgess \& Shallice, 1996; DeLuca, 1993; Gilboa \& Moscovitch, 2002). One of the pieces of evidence used to support such accounts has been the finding that confabulating neurological patients make increased numbers of intrusions in free recall (Cunningham et al., 1997; DeLuca, 1993) and increased numbers of false positive responses in recognition memory tests (Fischer et al., 1995; Gilboa, Alain, Stuss, Melo, Miller, \& Moscovitch, 2006). 
Along with episodic memory and executive function, semantic memory has been found to be a prominent area of neuropsychological abnormality in schizophrenia (for reviews, see Doughty \& Done, 2009; McKenna et al., 2002). It is, therefore, interesting that two studies have found that confabulation is associated with semantic memory impairment in the disorder. Dab et al. (2004), in the multiple single case study of schizophrenic patients cited above, found evidence of poor comprehension of the fables used to elicit confabulation, in the absence of a general deficit of comprehension. The patients who confabulated also made frequent errors on Collins and Quillian's (1969) "silly sentences" task, although one of their non-confabulating patients also made these. A group study by Lorente-Rovira et al. (2007) later found only weak evidence that confabulation was associated with poor performance on episodic memory tests, and there was no association with any of a range of executive tests; however, there were correlations with poor performance on both of two semantic memory tasks used in the study.

The aim of this study was to further examine the neuropsychological associations of confabulation in schizophrenia. We re-examined the finding of the relationship of confabulation to episodic and semantic memory impairment, and to different aspects of executive function. We also investigated the relationship between confabulation and intrusion errors in recall and false alarms in recognition tasks. Because general intellectual impairment is a feature of schizophrenia, which can by itself depress performance on specific neuropsychological tasks, we also restricted the sample to patients who met a criterion for relative preservation of general cognitive function.

\section{METHOD}

\section{Participants}

The patient sample consisted of 45 schizophrenic patients. They all met DSM IV criteria for schizophrenia and had mainly chronic illnesses (mean, $16.78 \pm 7.81$ years; range, 1 to 30 years). All patients were living in the community, either independently or with their families. They were selected on the basis that they were relatively cognitively preserved, defined as a Wechsler Adult Intelligence Scale, third revision (WAIS-III) IQ of $\geq 85$ based on four subtests: Information, Digit Symbol, Arithmetic and Block Design (Blyler, Gold, Iannone, \& Buchanan, 2000). All patients were on treatment with neuroleptic medication and were examined when they were in a clinically stable condition.

The control group consisted of 37 healthy volunteers. They were recruited so as to be similar to the patients in terms of age and education.

Both patients and controls were excluded if they had any physical disease affecting brain function, or head injury that had rendered them unconscious, or a history of drug or alcohol abuse.

All patients gave written informed consent to participate in the research. The study was approved by the local ethics committee.

\section{Procedure}

\section{Confabulation task}

This consisted of a Spanish translation of five fables previously used for eliciting confabulations in a structured setting (Lorente-Rovira et al., 2007). These are shown in the appendix. The subjects were read each story while also viewing the written text, and immediately after were asked to recall what they could. The subjects' responses were tape recorded and scored similarly to Nathaniel-James and Frith's (1996) method. A correctly recalled idea was scored as 1 , a partially recalled idea as $1 / 2$, and an idea not present in the story was coded as a confabulation. Minor errors or embellishments (e.g., referring to eyedrops instead of ointment in the story about a doctor treating a woman's eyes) and plausible extrapolations from events (e.g., saying "The dog wagged his tail and jumped on him" when the story only specified that the dog greeted his master) were not counted as confabulations. We also excluded statements which were perseverations from previous fables and those which reflected obvious thought disorder, or where the subject introduced obviously bizarre/delusional material (for more details of the scoring rules, see Lorente-Rovira et al., 2007).

Ratings of confabulation were made independently by two raters, one of whom had no knowledge of whether the subject was a patient or a control.

\section{Other neuropsychological tests}

Episodic memory. For this, we used the Spanish version of the California Verbal Learning Test (CVLT, Benedet \& Alejandre, 1998), which requires the subject to recall a list of 16 words over 5 trials. They then have to recall a new list of 16 words. There is then a further free recall of the first list, and also a cued recall. After $20 \mathrm{~min}$, the free and cued recall are repeated. Finally, the subjects have to recognize the items in the original word list from a list of 44 words. In addition to measures of correct responses on recall and recognition, we recorded intrusions in free and cued recall, and false positive responses in the recognition phase.

Semantic memory. We used Spanish translations of the same two tasks as in our earlier study (Lorente-Rovira et al., 2007). In the Semantic Verification Task (Laws, Humber, Ramsey, \& McCarthy, 1995), subjects are presented with a list of 56 sentences, half of which are true (e.g., Buses are driven) and half false (e.g., Geese have four legs), and have to respond true or false. In the Camel and Cactus Test (Bozeat, Lambon Ralph, Patterson, Garrard, \& Hodges, 2000), subjects are shown the written name of an object (e.g., camel) and have to decide which of four other words (tree, sunflower, cactus, or rose) it is most closely related to. There are 64 items in the test.

Executive function. The test battery here included several standard tests, including a working memory test (Letternumber sequencing from the WAIS-III), the Trail Making 
Test (Reitan \& Wolfson, 1993), the Stroop Color Word Test (Dyer \& Severence, 1973), and phonological (FAS Test) and semantic fluency (animals/1 minute). We also included three more recently devised tests. The Hayling Sentence Completion Test (Burgess \& Shallice, 1997) is a test of inability to inhibit verbal prepotent responses. The subject is read 15 sentences from which the last word is omitted and is required to give a word which does not make sense for completing the sentence. The test measures both time to respond and errors, but because schizophrenic patients show slowing on a wide range of tasks, for this study only errors were scored. The Brixton Test (Burgess \& Shallice, 1997) is conceptually similar to the Wisconsin Card Sorting Test. The subject is presented with many pages showing a rectangular array of 10 circles, one of which is colored blue. The colored circle moves around the array as the pages are turned, according to patterns that change without warning. The subject's task is to work out the pattern and say where the colored circle will be on the next page. In the Zoo Map from Behavioural Assessment of Dysexecutive Syndrome (BADS) (Wilson, Alderman, Burgess, Emslie, \& Evans, 1996), the subject has to draw a route which will enable him/her to visit several places in a zoo, while following certain rules.

\section{RESULTS}

Demographic and clinical findings for the patients and controls are shown in Table 1. The patients and controls were matched for age $(\mathrm{t}=1.65 ; p=.10)$ and years of education $(\mathrm{t}=-0.29 ; p=.90)$.

\section{Confabulation in the Schizophrenic Patients and Controls}

The inter-rater reliability for confabulation score was 0.90 $(p<.01)$ in the combined group of patients and controls. Therefore, in all analyses, the scoring of the non-blind rater, who had more experience in assessing confabulations, was used.

Table 1. Demographic and clinical characteristics (mean and SD) of schizophrenic patients and controls

\begin{tabular}{lcc}
\hline \hline & $\begin{array}{c}\text { Schizophrenia } \\
(N=45)\end{array}$ & $\begin{array}{c}\text { Controls } \\
(N=37)\end{array}$ \\
\hline Age (years) & $41.02(7.71)$ & $38.22(7.60)$ \\
Years of Education & $12.77(3.35)$ & $12.86(2.72)$ \\
Current IQ (WAIS-III) & $101.53(11.48)$ & - \\
Illness onset (years) & $22.35(4.58)$ & - \\
PANSS positive symptom score & $12.17(5.04)$ & - \\
PANSS negative symptom score & $19.25(8.42)$ & - \\
PANSS general & $26.14(5.75)$ & - \\
$\quad$ & & \\
\hline \hline
\end{tabular}

Note. WAIS-III, Wechsler Adult Intelligence Scale, third revision; PANSS, Positive and Negative Symptom Score.
The patients produced up to 10 items not present in the original story $($ mean $=2.73$ ), whilst controls produced a maximum of 3 confabulations $($ mean $=0.67)$ (see Figure 1$)$. Confabulations did not follow a normal distribution, and in the controls particularly there were large number of zeros. Therefore, a non-parametric test, the Kolmogorov-Smirnov two-sample test, was used to compare scores in the two groups. This difference was significant $(\mathrm{KS} \mathrm{Z}=1.99 ; p=$ .001). Examples of confabulations in both groups are shown in Table 2.

\section{Neuropsychological Test Scores in the Schizophrenic Patients and Controls}

Distributions of neuropsychological scores were tested for normality in the patients and controls using KolmogorovSmirnov one sample test. None were significantly different from normal. Test performance in the two groups was then compared using multivariate analysis of variance (MANOVA). The overall difference between the groups was significant (Hotelling $\mathrm{T}=1.89 ; F=2.84 ; p=.01$ ). Table 3 shows univariate $F$ tests. The patients performed significantly worse than healthy controls on all the tests.

\section{Neuropsychological Correlates of Confabulation}

In the patient group, relationships between confabulation and neuropsychological measures were examined using Pearson correlations, after square-root transforming the confabulation scores to normalize their distribution. To correct for multiple comparisons, we applied a false discovery rate correction which takes account of interdependencies among the measures (Benjamini \& Yekutieli, 2001); this is more appropriate than Bonferroni correction for neuropsychological data, where test results are likely to be intercorrelated, among other things because of their common loading on IQ. The findings are summarized in Table 4. It can be seen that, with correction, confabulation scores were correlated with poorer performance on none of the memory tests, both the semantic memory tests and one of the eight executive tests, the Brixton test.

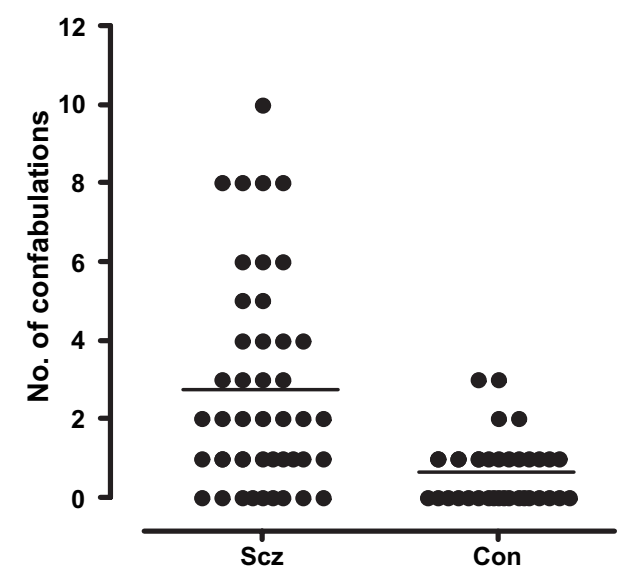

Fig. 1. Confabulation distribution in patients and controls. 
Table 2. Examples of confabulation in the schizophrenic patients and controls

\section{Patients}

Recalling fable 1: An old woman called a doctor, and as he didn't pay much attention to her, she then called a man to get his help.

Recalling fable 3: And the dog got very disappointed, because he didn't buy anything for it.

Recalling fable 4: But it [the donkey] couldn't cross (the river), although there would have been very big animals in it, such as jellyfish.

Recalling fable 4: These sponges soaked up all the water in the river.

Recalling fable 4: "Then, as it [the donkey] realized that it was floating, it said itself, "I am going to soak up the water with the sponges to make them float and avoid them getting wet".

Recalling fable 4: It wanted to take the salt with the sponges.

Controls

Recalling fable 2: All the passengers threw themselves into the sea to save themselves.

Recalling fable 2: The rich man didn't throw himself into the water and wanted to save all his wealth.

To examine the possibility that confabulation was occurring against a background of poor memory in schizophrenia, without being correlated with it, we plotted the patients' performance on immediate and delayed recall on the CVLT, using the $Z$-scores for normal adults available for the test. It can be seen from Figure 2 that confabulating patients (as defined as those with a score of $>3$, the upper limit for normal subjects) were fairly evenly distributed across all levels of memory performance and there was little to suggest that they clustered among those with poor memory. Some patients with recall performance in the normal range showed confabulation.

\section{Further Analysis of CVLT Performance and its Relationship to Confabulation}

As a measure of efficiency of encoding, we considered the semantic strategies used by the subjects in learning the list, and calculated CVLT semantic clustering scores. Also, to dissociate encoding and the retrieval processes, the clustering scores used at free recall task were also calculated. The schizophrenic patients used significantly less semantic clustering than the controls at learning $(9.63, S D=8.21 \mathrm{vs}$. 23.76, $S D=13.54, \mathrm{t}=-5.03 ; p<.0001)$ and also at free recall $($ mean $=6.02, S D=5.11 \mathrm{vs}$. mean $=14.03, S D=6.12$, respectively; $\mathrm{t}=-6.02 ; p<.0001)$. However, semantic clustering was not significantly correlated with confabulation score (transformed) either at learning $(\mathrm{r}=-0.21 ; p=.17)$ or at recall, although here there was a trend $(\mathrm{r}=0.28 ; p=.07)$.

Findings for intrusions and false recognition errors (raw scores) are shown in Table 5. Schizophrenic patients made significantly more intrusion errors overall (significant at cued recall, and at trend level at free recall) and more false recognition errors than healthy controls. Confabulation score in the patients (transformed) was significantly correlated with total intrusions (transformed) $(\mathrm{r}=0.39 ; p=.01)$,

Table 3. Neuropsychological performance of schizophrenic patients and controls

\begin{tabular}{|c|c|c|c|c|}
\hline & Schizophrenia $(N=45)$ & Controls $(N=37)$ & $\mathrm{F}$ & $p$ \\
\hline \multicolumn{5}{|l|}{ Memory } \\
\hline CVLT Immediate Recall 1-5 & $42.73(13.16)$ & $60.05(10.47)$ & 41.83 & 0.000 \\
\hline Semantic cues at learning phase & $9.63(8.21)$ & $23.76(13.54)$ & 30.35 & 0.000 \\
\hline CVLT Free Recall & $18.27(6.64)$ & $26.59(4.55)$ & 41.63 & 0.000 \\
\hline Semantic cues at recall phase & $6.02(5.11)$ & $14.03(6.12)$ & 36.29 & 0.000 \\
\hline CVLT Cued Recall & $19.25(5.89)$ & $27.70(4)$ & 54.81 & 0.000 \\
\hline CVLT Recognition & $13.98(1.90)$ & $15.30(1.10)$ & 13.92 & 0.001 \\
\hline \multicolumn{5}{|l|}{ Semantic memory } \\
\hline Verification Test (error score) & $2.98(2.23)$ & $1.31(1.35)$ & 15.24 & 0.000 \\
\hline Camel \& Cactus Test (correct responses) & $53.02(5.73)$ & $57.78(2.02)$ & 23.09 & 0.000 \\
\hline \multicolumn{5}{|l|}{ Executive function } \\
\hline Number-Letter sequencing & $8.53(2.64)$ & $11.44(2.19)$ & 26.67 & 0.000 \\
\hline Trailmaking Test $(\mathrm{B}-\mathrm{A})^{1}$ & $79.82(55.49)$ & $35.89(23.27)$ & 19.69 & 0.000 \\
\hline Stroop test time $(\mathrm{WC}-\mathrm{W})^{2}$ & $87.03(43.36)$ & $60.76(19.15)$ & 10.68 & 0.002 \\
\hline Hayling Test (scaled score) & $4.64(2.44)$ & $6.38(1.69)$ & 13.38 & 0.000 \\
\hline Brixton Test (scaled score) & $5.60(2.30)$ & $6.64(1.79)$ & 4.76 & 0.032 \\
\hline BADS Zoo Map & $8.89(3.78)$ & $12.00(3.06)$ & 8.46 & 0.005 \\
\hline Phonological Fluency & $27.76(11.00)$ & $44.14(11.21)$ & 43.62 & 0.000 \\
\hline Semantic Fluency & $17.18(4.54)$ & $23.17(4.71)$ & 33.66 & 0.000 \\
\hline
\end{tabular}

Note. CVLT, the California Verbal Learning Test; BADS, Behavioural Assessment of Dysexecutive Syndrome.

${ }^{1}$ Score on part B minus score on part A.

${ }^{2}$ Time in seconds on incongruous condition (word-color) minus time on congruous condition (word). 
Table 4. Correlations between confabulation scores and neuropsychological test scores in the schizophrenic patients

\begin{tabular}{lcc}
\hline \hline & $\begin{array}{c}\text { Confabulation } \\
\text { Pearson correlation }\end{array}$ & $p$ \\
\hline Memory & & \\
Recall of fables & -0.38 & 0.01 \\
CVLT Immediate Recall 1-5 & -0.28 & 0.06 \\
CVLT Recognition & -0.26 & 0.09 \\
Semantic memory & & \\
Verification Test (error score) & 0.44 & $0.003^{*}$ \\
Camel \& Cactus Test (correct responses) & -0.47 & $0.001^{*}$ \\
Executive function & & \\
Number-letter sequencing & -0.28 & 0.07 \\
Trailmaking Test (B-A) & 0.04 & 0.79 \\
Stroop Test (WC-W) & 0.04 & 0.80 \\
Hayling Test (scaled score) & -0.16 & 0.28 \\
Brixton Test (scaled score) & -0.46 & $0.002 *$ \\
BADS Zoo Map & -0.44 & 0.006 \\
Phonological Fluency & 0.07 & 0.63 \\
Semantic Fluency & -0.25 & 0.10 \\
\hline \hline
\end{tabular}

Note. CVLT, the California Verbal Learning Test; BADS, Behavioural Assessment of Dysexecutive Syndrome.

*Significant after correction using false discovery rate.

intrusions produced in free recall $(\mathrm{r}=0.43 ; p=.004)$, and marginally with intrusions in cued recall $(\mathrm{r}=0.29 ; p=.05)$. However, there was no significant correlation with false positive recognition errors $(\mathrm{r}=0.21 ; p=.18)$.

\section{DISCUSSION}

The present study, like several previous studies, documents the occurrence of a form of provoked confabulation in schizophrenia (Dab et al., 2004; Lorente-Rovira et al., 2007; Nathaniel-James \& Frith, 1996; Salazar-Fraile et al., 2004). In terms of its patterns of correlation with memory, executive, and other neuropsychological variables, there was evidence for both similarities and differences with the phenomenon as seen in neurological disease.

In neurological disorders, memory impairment is a prerequisite for confabulation. This principle does not appear to hold true for schizophrenia: in the present study, the only memory measure which showed an association with confabulation was poor recall of the fables used to elicit it, and this did not withstand correcting for multiple comparisons. Nor did it seem to be the case that memory impairment was playing a "permissive" role for confabulation to occurconfabulating patients were found at all levels of memory performance, both intact and impaired. Our findings thus support and strengthen those of previous studies which have concluded that episodic memory impairment is neither necessary nor sufficient for confabulation in schizophrenia (Dab et al., 2004; Lorente-Rovira et al., 2007; NathanielJames \& Frith, 1996; Nathaniel-James et al., 1996; SalazarFraile et al., 2004).

While there is clear, if not completely consistent, evidence that confabulation is associated with executive impairment in neurological patients, the findings on this point in schizophrenia, as noted in the introduction, have been decidedly mixed. In the present study, we found an association with one of eight executive tests, the Brixton test. Given that we previously failed to find an association with confabulation in schizophrenia on this test (Lorente-Rovira et al., 2007), and other studies have had conflicting findings with respect to other tests (Dab et al., 2004; Lorente-Rovira et al., 2007; Nathaniel-James et al., 1996; Salazar-Fraile et al., 2004), one interpretation might be that the executive deficit associated with confabulation, if there is one, is simply not well captured by existing tests, as Turner et al. (2008) have argued for in neurological disease. On the other hand, it is noteworthy that the Brixton Test embodies aspects of strategic planning, cognitive flexibility and monitoring for errors, features that play an important role in current theoretical approaches to confabulation which emphasize a failure of retrieval processes in memory. Thus, Moscovitch and co-workers (Gilboa \& Moscovich, 2002; Gilboa et al.,
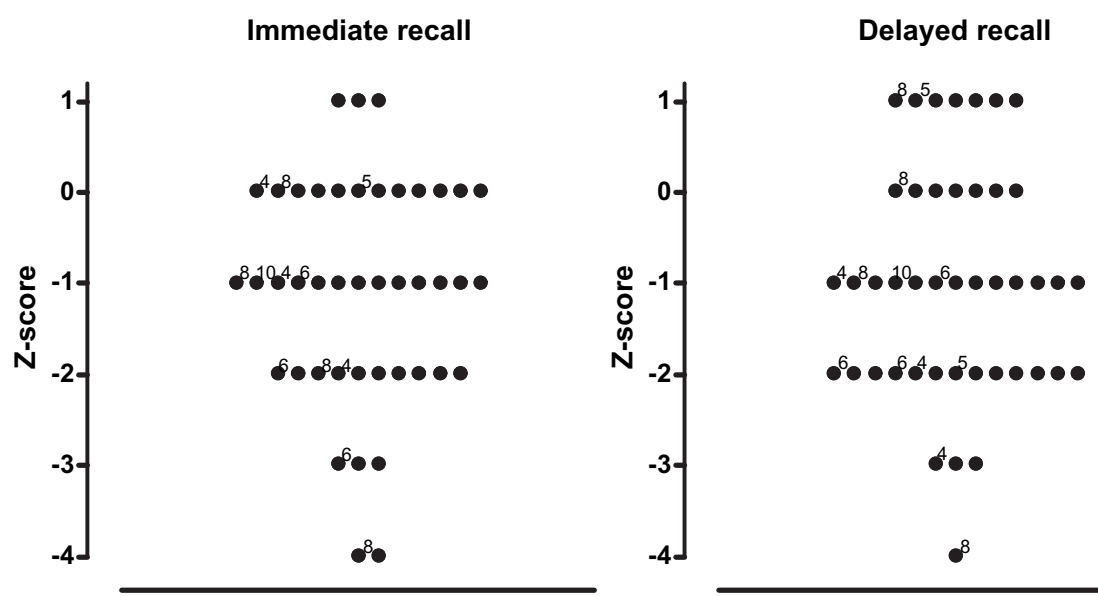

Fig. 2. Confabulation in schizophrenic patients showing different levels of memory performance, based on normative data for the California Verbal Learning Test (CVLT) recall. Confabulators are indicated by symbols with a superscript number; the number indicates the number of confabulations produced. Non-confabulators (i.e., those who produced 0-3 confabulations) have no superscript number. 
Table 5. T test comparing intrusion and false recognition memory errors (transformed) in patients and controls (descriptives are shown for raw scores)

\begin{tabular}{lcccc}
\hline \hline & $\begin{array}{c}\text { Schizophrenia } \\
(N=45)\end{array}$ & $\begin{array}{c}\text { Controls } \\
(N=37)\end{array}$ & $\mathrm{t}$ & $\mathrm{p}$ \\
\hline Free recall intrusions & $1.55(2.05)$ & $0.83(1.28)$ & 1.84 & 0.07 \\
Cued recall intrusions & $3.02(3.11)$ & $0.86(1.53)$ & 4.57 & 0.000 \\
Total intrusions & $4.57(4.63)$ & $1.69(2.69)$ & 3.95 & 0.000 \\
False positive & $2.32(2.31)$ & $0.86(0.98)$ & 3.13 & 0.002 \\
$\quad$ recognition errors & & & & \\
\hline \hline
\end{tabular}

2006; Moscovitch \& Melo, 1997) have argued that when a target memory is not immediately elicited by a cue, a strategic search mechanism is initiated. This operates at the input stage to initiate and constrain the search for further potential cues. Once a new candidate memory is recovered, it also operates to verify whether the memory should be accepted as valid. The similar, but more complicated, model of Burgess and Shallice (1996) distinguishes three different components of strategic retrieval. One of these, as in the model of Moscovitch and co-workers, acts at the input stage. The other two operate at the output stage: an "editor," which continuously checks the output against memories previously retrieved during the task to make sure that they fit with these, and a "mediator," which carries out a more controlled, problem-solving checking, concerning the adequacy and plausibility of retrieved memory elements. Impairment of this last process is considered to result in reasoning errors leading to fantastic or bizarre responses.

We found a correlation between confabulation and intrusion errors in recall. This has also been found in confabulating neurological patients and has been interpreted as supporting a role for a monitoring deficit in confabulation (DeLuca, 1993). However, our failure to find a correlation with false positive recognition errors does not fit with such an account, because these should also be vulnerable to monitoring dysfunction. Nevertheless, there is arguably a difference between intrusions in free recall and false positive responses in recognition. Free recall is vulnerable to an input stage dysfunction; specifically errors here would be the result of a too-loosely constrained search for further cues when the correct memory is not immediately recovered. Recognition, on the other hand, is not susceptible to input stage dysfunction because the (correct) cue is externally provided. One might envisage a gradient of correlation between different error types and confabulation, with intrusions in free recall showing the highest association, because dysfunction in both input and output strategic searches have the potential to affect responding; intrusions in cued recall showing less association, because the input search is assisted by the semantic cues provided; and finally false positive responses in recognition showing least association, because input stage problems cannot contribute. This argument would imply a difference between the strategic search dysfunctions responsible for confabulation in neurological disease and schizo- phrenia: in neurological patients the monitoring process (output stage) is crucial (cf Gilboa et al., 2006), whereas in schizophrenia it is predominantly the input stage that is defective.

Replicating our own earlier study (Lorente-Rovira et al., 2007), and in line with the findings of Dab et al. (2004), we found a significant association between confabulation and semantic memory impairment. How then might semantic memory impairment be relevant to confabulation in schizophrenia? It is tempting to speculate that schizophrenic confabulation might be the outcome of the kind of defective strategic retrieval system envisioned by Moscovitch and coworkers (Gilboa \& Moscovich, 2002; Gilboa et al., 2006; Moscovitch, 1989, 1992) and Burgess and Shallice (1996) interacting not, as Baddeley (1990) put it, with a hazy episodic memory, but instead with defective semantic memory. Such a proposal would entail that schizophrenic confabulations should have different features than neurological confabulations. However, there are already suggestions that this is the case. Nathaniel-James and Frith (1996) in their original study considered that schizophrenic confabulations seemed to involve reorganizing and reconstructing elements in the original story, rather than the invention of completely new material which characterizes neurological confabulations. Lorente-Rovira et al. (2007) found that there was both re-organized and new material in the confabulations produced by their schizophrenic patients; however, the kind of gross inventions described in patients with amnesia and dementia (e.g., see Kopelman, 1987) were not seen, and the confabulations were generally constrained by the context of the story. These are features that perhaps might be expected for confabulation based on semantic rather than episodic memory dysfunction.

\section{ACKNOWLEDGMENTS}

This work was supported by the Instituto de Salud Carlos III, Centro de Investigación en Red de Salud Mental, CIBERSAM. The authors have no conflict of interest.

\section{REFERENCES}

Baddeley, A.D. (1990). Human memory. London: Lawrence Erlbaum Associates.

Baddeley, A.D., \& Wilson, B. (1988). Frontal amnesia and the dysexecutive syndrome. Brain and Cognition, 7, 212-230.

Benedet, M.J., \& Alejandre, M.A. (1998). Test de Aprendizaje Verbal España-Complutense (TAVEC). TEA. Publicaciones de Psicología Aplicada.

Benjamini, Y., \& Yekutieli, D. (2001). The control of the false discovery rate in multiple testing under dependency. Annals of Statistics, 29, 1165-1188.

Blyler, C.R., Gold, J.M., Iannone, V.N., \& Buchanan, R.W. (2000). Short form of the WAIS-III for use with patients with schizophrenia. Schizophrenia Research, 46, 209-215.

Bozeat, S., Lambon Ralph, M.A., Patterson, K., Garrard, P., \& Hodges, J.R. (2000). Non-verbal semantic impairment in semantic dementia. Neuropsychologia, 38, 1207-1215.

Burgess, P.W., \& Shallice, T. (1996). Confabulation and the control recollection. Memory, 4, 359-411. 
Burgess, P.W., \& Shallice, T. (1997). The Hayling and Brixton Tests. Bury St Edmunds, England: Thames Valley Company Limited.

Collins, A.M., \& Quillian, M.R. (1969). Retrieval time from semantic memory. Journal of Verbal Learning and Verbal Behaviour, 8, 240-247.

Cunningham, J.M., Pliskin, N.H., Cassisi, J.E., Tsang, B., \& Rao, S.M. (1997). Relationship between confabulation and measures of memory and executive function. Journal of Clinical and Experimental Neuropsychology, 19, 867-877.

Dab, S., Claes, T., Morais, J., \& Shallice, T. (1999). Confabulation with a selective descriptor process impairment. Cognitive Neuropsychology, 16, 215-242.

Dab, S., Morais, J., \& Frith, C. (2004). Comprehension, encoding, and monitoring in the production of confabulation in memory: A study with schizophrenic patients. Cognitive Neuropsychiatry, 9, 153-182.

Delbecq-Derouesné, J., Beauvois, M.F., \& Shallice, T. (1990). Preserved recall versus impaired recognition. A case study. Brain, 113, 1045-1074.

DeLuca, J. (1993). Predicting neurobehavioral patterns following anterior communicating artery. Cortex, 29, 639-647.

DeLuca, J. (2000). A cognitive neuroscience perspective on confabulation. Neuropsychoanalysis, 2, 119-132.

Doughty, O.J., \& Done, D.J. (2009). Is semantic memory impaired in schizophrenia? A systematic review and meta-analysis of 91 studies. Cognitive Neuropsychiatry, 14, 473-509.

Dyer, F.N., \& Severance, L.J. (1973). Stroop interference with successive presentations of separate incongruent words and colors. Journal of Experimental Psychology, 98, 438-439.

Fischer, R.S., Alexander, M.P., D’Esposito, M., \& Otto, R. (1995). Neuropsychological and neuroanatomical correlates of confabulation. Journal of Clinical and Experimental Neuropsychology, $17,20-28$

Gilboa, A., Alain, C., Stuss, D.T., Melo, B., Miller, S., \& Moscovitch, M. (2006). Mechanisms of spontaneous confabulations: A strategic retrieval account. Brain, 129, 1399-1414.

Gilboa, A., \& Moscovitch, M. (2002). The cognitive neuroscience of confabulation: A review and model. In A.D. Baddeley, M.D. Kopelman, \& B.A. Wilson (Eds.), Handbook of memory disorders (2nd ed., pp. 315-342). Chichester: Wiley.

Glowinski, R., Payman, V., \& Frencham, K. (2008). Confabulation: A spontaneous and fantastic review. Australian and New Zealand Journal of Psychiatry, 42, 932-940.

Hashimoto, R., Tanaka, Y., \& Nakano, I. (2000). Amnesic confabulatory syndrome after focal basal forebrain damage. Neurology, 54, 978-980.

Heinrichs, R.W., \& Zakzanis, K.K. (1998). Neurocognitive deficit in schizophrenia: A quantitative review of the evidence. Neuropsychology, 12, 426-445.

Kopelman, M.D. (1987). Two types of confabulation. Journal of Neurology, Neurosurgery, and Psychiatry, 50, 1482-1487.

Kraepelin, E. (1913). Dementia Praecox and Paraphrenia (trans. R.M. Barclay, 1919). Edinburgh: Livingstone.

Kramer, S., Bryan, K.L., \& Frith, C.D. (1998). "Confabulation" in narrative discourse by schizophrenic patients. International Journal of Language and Communication Disorders, 33(Suppl.), 202-207.

Laws, K.R., Humber, S.A., Ramsey, D.J., \& McCarthy, R.A. (1995). Probing sensory and associative semantics for animals and objects in normal subjects. Memory, 3, 397-408.

Lorente-Rovira, E., Pomarol-Clotet, E., McCarthy, R.A., Berrios, G.E., \& McKenna, P.J. (2007). Confabulation in schizophrenia and its relationship to clinical and neuropsychological features of the disorder. Psychological Medicine, 3, 1403-1412.

McKenna, P.J. (2007). Schizophrenia and related syndromes (2nd ed.). Hove: Routledge.

McKenna, P.J., Lorente-Rovira, E., \& Berrios, G.E. (2009). Confabulation as a psychiatric symptom. In W. Hirstein (Ed.), Confabulation: Views from neuroscience, psychiatry, psychology and philosophy (pp. 159-172). New York: Oxford University Press.

McKenna, P.J., Ornstein, T., \& Baddeley, A.D. (2002). Schizophrenia. In A.D. Baddeley, M.D. Kopelman, \& B.A. Wilson (Ed.), The handbook of memory disorders (pp. 413-435). New York: John Wiley \& Sons, Ltd.

Mercer, B., Wapner, W., Gardner, H., \& Benson, D.F. (1977). A study of confabulation. Archives of Neurology, 34, 429-433.

Moscovitch, M. (1989). Confabulation and the frontal systems: Strategic versus associative retrieval in neuropsychological theories of memory. In H.L. Roediger \& F.I.M. Craik (Eds.), Varieties of memory and consciousness: Essays in honor of Endel Tulving (pp. 133-160). Hillsdale, NJ: Lawrence Erlbaum Associates.

Moscovitch, M. (1992). Memory and working-with-memory: A component process model based on modules and central systems. Journal of Cognitive Neuroscience, 4, 257-267.

Moscovitch, M., \& Melo, B. (1997). Strategic retrieval and the frontal lobes: Evidence from confabulation and amnesia. Neuropsychologia, 35, 1017-1034.

Nathaniel-James, D.A., Foong, J., \& Frith, C.D. (1996). The mechanisms of confabulation in schizophrenia. Neurocase, 2, 475483.

Nathaniel-James, D.A., \& Frith, C.D. (1996). Confabulation in schizophrenia: Evidence of a new form? Psychological Medicine, 26, 391-399.

Reichenberg, A., \& Harvey, P.D. (2007). Neuropsychological impairments in schizophrenia: Integration of performance-based and brain imaging findings. Psychological Bulletin, 133, 833858.

Reitan, R.M., \& Wolfson, D. (1993). The Halstead-Reitan neuropsychological test battery: Theory and clinical applications (2nd ed.). Tucson, AZ: Neuropsychological Press.

Salazar-Fraile, J., Tabarés-Seisdedos, R., Selva-Vera, G., BalanzáMartinez, V., Martinez-Arán, A., Catalán, J., et al. (2004). Recall and recognition confabulation in psychotic and bipolar disorders: Evidence for two different types without unitary mechanisms. Comprehensive Psychiatry, 45, 281-288.

Schnider, A. (2008). The confabulating mind. How the brain creates reality. New York: Oxford University Press.

Simpson, J., \& Done, D.J. (2002). Elasticity and confabulation in schizophrenic delusions. Psychological Medicine, 32, 451-458.

Stuss, D.T., Alexander, M.P., Lieberman, A., \& Levine, H. (1978). An extraordinary form of confabulation. Neurology, 28, 11661172.

Turner, M.S., Cipolotti, L., Yousry, T.A., \& Shallice, T. (2008). Confabulation: Damage to a specific inferior medial prefrontal system. Cortex, 44, 637-648.

Wilson, B.A., Alderman, N., Burgess, P.W., Emslie, H.C. \& Evans, J.J. (1996). The behavioural assessment of the dysexecutive syndrome. Flempton, Bury St Edmunds: Thames Valley Test Company.

Wing, J.K., Cooper, J.E., \& Sartorius, N. (1974). The measurement and classification of psychiatric symptoms. New York: Cambridge University Press. 


\section{APPENDIX:}

\section{FABLES USED TO ELICIT CONFABULATION}

\section{Story 1}

An elderly woman /, who lived in a house / full of beautiful paintings and ornaments /, asked her doctor / to treat her sore eyes / . The doctor came / and put ointment / on her eyelids /, but while she sat / with her eyes closed /, he stole / one or two valuable possessions / . Each time he visited /, he took another item /, until the old woman's house was almost bare / . One day / he arrived to treat her /, but he found two policeman / waiting to arrest him / . "I'm not a thief!" / he said / . "I didn't say you were a thief", / said the old lady, / "but you are a bad doctor /. Before you cured my eyes /, I could see all my belongings / . Now I can't see any of them / ."

\section{Story 2}

A rich man / took a valuable cargo / on a voyage / across dangerous seas / . A storm soon blew up / and the ship went down / throwing the passengers / into the sea / . They all began to swim / for their lives / except the rich man / who raised his arms to heaven / and promised his god / all kinds of riches / if he saved $\mathrm{him} /$. The other passenger shouted / to the praying man , / "Don't leave it for God to save you / , swim for yourself."

\section{Story 3}

A cowboy / went to San Francisco / with his dog, / which he left at a friend's / while he went to buy a new suit of clothes. / Dressed in his grand new suit, / he came back to the dog, / whistled to it, / called it by name / and patted it. / But the dog would have nothing to do with him / in his new hat and coat / and gave a mournful howl. / Coaxing was of no avail, / so the cowboy went away / and put on his old suit, / and then the dog immediately showed its wild joy / on seeing its master as it thought he ought to be.

\section{Story 4}

A donkey, / loaded with salt, / had to wade a stream. / He fell down / and for a few minutes / lay comfortably in the cool water. / When he got up, / he felt relieved of a great part of his burden, / because the salt had melted in the water. / Long-ears noted this advantage / and at once applied it the following day / when, loaded with sponges, / he again went through the same stream. / This time he fell purposely / but was grossly deceived. / The sponges had soaked up the water / and were considerably heavier than before. / The burden was so great that he fell / and could not go on.

\section{Story 5}

A laborer / worked along a stream. / His axe fell in / and, as he could not get it out, / he sat on the bank / and bemoaned his fate. / Neptune / took pity on the man's poverty, / dived / and brought up a golden axe. / The laborer said it was not his. / Neptune dived again / and appeared with a silver axe. / The laborer made no claim. / Again the god dived / and brought up the right iron axe / with the wooden handle. / "That is it!", / the laborer exclaimed. / "I wanted to test you", / replied Neptune. / "I am glad you are as honest as you are poor. / Take all the three axes". 
Reproduced with permission of the copyright owner. Further reproduction prohibited without permission. 